\title{
The Role of Hospitalists in the Acute Care of Stroke Patients
}

\author{
Alpesh Amin, MD, MBA, FHM \\ David Likosky, MD, FHM
}

\author{
Address \\ *University of California, Irvine, 101 The City Drive, Building 26, Room 1005, \\ ZC-4076H, Orange, CA 92868, USA \\ Email: anamin@uci.edu \\ Published online: 30 March 2010 \\ (C) The Author(s) 2010. This article is published with open access at Springerlink.com
}

\section{Opinion statement}

Stroke care has become progressively more complicated with advances in therapies necessitating timely intervention. There are multiple potential providers of stroke care, which traditionally has been the province of general neurologists and primary care physicians. These new players, be they vascular neurologists, neurohospitalists, internal medicine hospitalists, or neurocritical care physicians, at the bedside or at a distance, are poised to make a significant impact on our care of stroke patients. The collaborative model of care may be or become the most prevalent as physicians apply their distinct skill sets to the complex care of inpatients with cerebrovascular disease.

\section{Introduction}

Approximately 795,000 strokes occur each year in the United States, along with 200,000 to 500,000 transient ischemic attacks. Stroke continues to rank third among all causes of death nationally, and approximately $47 \%$ of those deaths occur in the hospital. It is estimated that $6.5 \%$ to $15 \%$ of stroke patients experience their stroke while in the hospital [1]. In 2006, 889,000 patients were discharged from short-stay hospitals with the primary diagnosis of stroke. Stroke remains a leading cause of long-term disability, with an estimated direct and indirect cost in 2010 of $\$ 73.7$ billion [2•].
Many physicians have felt we have little to offer patients with ischemic stroke; however, dramatic advances in the diagnosis and treatment of these patients have rendered that attitude progressively baseless. With the advent of a new group of physicians dedicated to inpatient care-hospitalists-it is imperative that these specialists, as well as other dedicated inpatient physicians, learn to manage stroke patients and develop systems to optimize stroke care. 
- Stroke care has moved beyond the proverbial "take two aspirin" paradigm to one in which timely and aggressive care is the expectation of both patients and external organizations. With the advent of intravenous tissue plasminogen activator (IV tPA) in 1995, stroke became a de facto emergency [3]. With current guidelines recommending the use of IV tPA up to $4.5 \mathrm{~h}$ after the event, data for intraarterial tPA out to $6 \mathrm{~h}$, and the approval of mechanical clot retrieval devices for use out to $8 \mathrm{~h}$, a dramatic change in approach has occurred $[4 \bullet, 5-7]$.

- Adoption of the most aggressive therapies for stroke has been quite slow because of concerns regarding safety, liability, and specialty participation in the evaluation and decision to treat [8]. The 2000 Brain Attack Coalition and 2005 American Heart Association/ American Stroke Association recommendations for the establishment of stroke systems of care have helped "promote patient access to the full range of activities and services associated with stroke prevention, treatment, and rehabilitation" $[9,10]$. In addition, the Joint Commission program for disease-specific certification for stroke, based on the Brain Attack Coalition recommendations for comprehensive stroke centers, has effected great change [11]. However, these programs and guidelines are voluntary. Many states and communities have diverted acute stroke patients to hospitals that either are certified or have met other criteria demonstrating a commitment to stroke care. About 700 of the approximately 5700 hospitals in the United States have a Joint Commission-certified stroke center.

- The elements of stroke care therefore have moved far beyond the acute bedside treatment of individual patients. A patient now is seen in the context of population measures of appropriate care as well as his or her place in the continuum of disease management. There is a necessary emphasis on acute treatments but also on initiation of appropriate secondary prevention, such as antiplatelet agents, treatment of hypertension and hyperlipidemia, evaluation by rehabilitation therapists, and diligent avoidance of complications. In the past, these measures occurred on an ad hoc basis and frequently some were omitted, particularly when individual providers saw a low volume of inpatients with cerebrovascular disease. Beyond these measures, there is a significant emphasis on education. Patients are expected to receive education on their disease process, prevention, therapies, and the need to seek acute medical attention for recurrent events. In addition, physicians are expected to provide education to the hospital staff to enable them to care for patients with cerebrovascular disease.

- Reporting systems (both voluntary and otherwise) have made systemic lapses in care more transparent and likely will do so even more in the future, with associated financial impacts on both hospitals and individual providers. Physicians who provide inpatient care now 
- At present, there are many different types of physicians providing stroke care, each with potential strengths and weaknesses. These physicians range from primary care providers with limited access to neurologists to a gamut of neurology specialists, both on-site and remote. At present, it is not clear whether one model is superior, and this answer likely will vary depending on the practice environment.

- Internal medicine hospitalists frequently are requested to participate in the care of hospitalized patients with many different diagnoses. This is a result of both their clinical success and the rapid rise in the number of practicing hospitalists. According to a 2007 survey of the American Hospital Association, there were 28,000 hospitalists practicing in 2838 hospitals nationally. However, the typical internal medicine hospitalist's training may include only a minimal amount of inpatient neurology experience. A significant concern on the part of many hospitalists is the pressure to assume the care of patients with clinical conditions outside their scope of expertise/practice. On the other hand, hospitalists trained in internal medicine have to take care of stroke patients because there is a paucity of neurologists willing to care for inpatient stroke patients nationally [12].

- However, the core strengths of hospitalists may well be a valuable asset in the care of stroke patients. Hospitalists are well trained in the management of hypertension, diabetes, hyperlipidemia, and other comorbidities associated with stroke patients. In addition, hospitalists are expert in treating many complications of stroke, including aspiration pneumonia, urinary tract infections, and thromboembolic disease, and typically can do so in a very timely fashion. They have been integral to the quality movement nationally and are well versed in the machinations of the hospital. Protocol and pathway development is a hospitalist core competency [13]. Furthermore, by virtue of their presence in the hospital setting, hospitalists can respond to complications, both medical and neurologic, in a very short time 
frame-far shorter than that of an offsite neurologist with a busy practice. Whether as a sole provider or a team participant in the care of stroke patients, hospitalists have much to offer, particularly in areas without access to neurologists, given the present ratio of 4.0 neurologists per 100,000 persons in the United States [14].

- Neurologists remain the experts in the realm of cerebrovascular disease. The variety and specificity of training they bring to bear have increased dramatically over the past decade. General neurologists frequently maintain both inpatient and outpatient practices. Indeed, many neurologists with specialization other than stroke continue to care for these patients as part of their call rotation. As in many other areas of medicine, care has become increasingly complicated.

Vascular neurology has arisen as a specialty to address this issue. The grandfathering period for board certification has passed, and future vascular neurologists will have to complete a vascular neurology fellowship. These physicians will be expected to be experts in stroke program management and quality work, given how integral these are to modern stroke care.

- Beyond these groups of neurologists are two other relatively new specialists. Neurocritical care physicians, by necessity, care for stroke patients, including those who are most ill. Their practice moves beyond stroke to cover general neurology, trauma, and other lifethreatening neurologic illnesses. Many, however, focus exclusively on critical care, limiting their ability to see most stroke inpatients. Neurohospitalists, the newest group, focus their care on inpatients with neurologic disease [11]. Although this field remains to be fully defined, it appears to be gaining momentum, with more than 280 members of the newly founded section of the American Academy of Neurology (N. Poechmann, personal communication, American Academy of Neurology, 2009). These physicians are expected to combine the inpatient, quality, and systems improvement expertise of the internal medicine hospitalist with the skills of a general neurologist, and may be part of the answer to workforce concerns regarding acute stroke care [11]. Although relatively small at present, this group of physicians has great potential to affect inpatient neurologic care.

- An additional resource is telemedicine. Neurologically underserved areas may now avail themselves of these services. Through telemedicine, neurologists participate in the care of stroke patientsparticularly in the emergent evaluation for thrombolysis-at a distance, using interactive audiovisual connections, allowing them, for example, to review diagnostic imaging. Several potential issues are raised in this model of care, including physician licensure and credentialing, patient privacy, physician reimbursement, and medical liability. These issues are well covered in a recent American Heart Association guideline [15]. This model of practice has had considerable success and appears to be a viable way to use the limited resource of neurologic expertise. 
- Hospitalists frequently are the primary providers of inpatient stroke care despite an underemphasis on neurology in traditional internal medicine training. Although neurology is not an internal medicine subspecialty, it frequently is treated as such. The relationship between hospitalists and neurologists is critically important to quality patient care. The dynamics of that relationship are affected by many factors but have been ill defined.

- With the publication of the Core Competencies for Hospital Medicine [12], the field is becoming more clearly delineated. The role of the hospitalist in the care of patients with cerebrovascular disease remains unclear. Included in the core competencies are the need to "recognize the indications for early specialty consultation" and the expectation that a hospitalist might "lead, coordinate or participate in multidisciplinary teams" [13]. One concern, however, is whether hospitalists feel comfortable with or are properly trained by traditional internal medicine residency programs to care for stroke patients. A national survey conducted by Plauth et al. [16] revealed an inadequacy in neurology training during internal medicine residency out of proportion to the need for this training in clinical practice.

- A 2006 study of billing data from 44,099 stroke patients from 1998 to 2000 found that $18 \%$ of stroke patients were seen solely by a generalist (defined as a family practitioner, internist, or general practitioner), $17 \%$ solely by a neurologist, and $60 \%$ by both. Although patients seen only by a neurologist tended to have more severe strokes, they were $12 \%$ less likely to be rehospitalized for infection or aspiration pneumonitis $[16,17]$. During the period studied, the hospitalist field was just beginning to gain traction nationally. This trend, in addition to the advent of the Joint Commission-certified stroke centers, has made prophylaxis against infection and other metrics of stroke quality of care much more matter of course.

- A survey was developed focusing on three areas of stroke care. The first section assessed hospitalists' views of data for IV tPA as well as for the use of IV heparin in acute stroke and atrial fibrillation. The second section evaluated respondents' approach to secondary prevention. The final section surveyed respondents' attitudes toward the best providers of care and their relationships with neurologists at their institutions. (Fig. 1).

- The Society of Hospital Medicine sent 2062 survey invitations to its membership; 206 complete responses were received via the Zoomerang online survey service [18]. Despite only about a $10 \%$ rate of response to the survey, the results are as follows: A minority of hospitalists (82, or $40 \%)$ consult a neurologist for all ischemic stroke patients, and 34\% (69) have difficulty accessing a neurologist at their hospital. Only 10\% (20), however, feel a neurologist must be 


\section{Please circle your answer}

ACUTE STROKE

1. Would you use IV heparin for a 70-year-old patient with atrial fibrillation and new-onset stroke (moderate aphasia and right-sided weakness) that started 6 hours ago? The CT scan is negative for bleed, patient was not on warfarinand BP is $140 / 80 \mathrm{~mm} \mathrm{Hg}$.

YES NO

2. Do you think IV tissue plasminogen activator (tPA) is a proven treatment for acute stroke if treatment can be given within 3 hours of stroke onset?

YES NO

STROKE PREVENTION

1. Would you prescribe a statin to a patient with symptomatic carotid stenosis of $60 \%$ with $\mathrm{LDL}$ of $95 \mathrm{mg} / \mathrm{dL}$ ?

YES

$\mathrm{NO}$

2. When would you consider carotid endarterectomy for a patient with asymptomatic stenosis?
$90 \%-99 \%$
$80 \%-99 \%$
$70 \%-99 \%$
$60 \%-99 \%$
$50 \%-99 \%$
Never

3. For a patient with asymptomatic carotid stenosis of $60 \%-99 \%$, who would you refer the patient to?

$\begin{array}{ccc}\text { No one } & \text { Cardiologist Neurologist } & \text { Neurosurgeon } \\ \text { Vascular surgeon } & \end{array}$

4. What do you think is the optimal long-term SBP for a patient who had a carotid endarterectomy 2 months previously?
$<150$
$<140$
$<130$
$<120$

5. Would you be comfortable randomly assigning your patients with asymptomatic carotid stenosis to carotid endarterectomy or carotid stenting?
$\mathrm{NO}$, endarterectomy is proven
$\mathrm{NO}$, medical treatment is preferred

YES

6. What is your preferred medication for patients who are in sinus rhythm and have a TIA or stroke despite taking $81 \mathrm{mg}$ aspirin per day for prophylaxis?

$$
\begin{gathered}
325 \mathrm{mg} \text { aspirin } \quad 650 \mathrm{mg} \text { aspirin } \quad \text { Clopidogrel (Plavix) } \\
\text { Warfarin } \\
\text { WHO CARES FOR STROKE PATIENTS? }
\end{gathered}
$$

1. Approximately what percent of stroke patients are seen by a neurologist at your hospital?

$$
0-10 \quad 11-30 \quad 31-50 \quad 51-75
$$

Preferred alternative:

$$
\text { None Some Most All }
$$

2. Do you consult a neurologist for all ischemic stroke patients?

$$
\text { YES NO }
$$

3. Is it difficult to get a neurologist to see a stroke patient at your institution?

$$
\text { YES NO }
$$

4. Does the difficulty in getting neurologic consultation prevent you from consulting a neurologist for stroke patients?

YES NO

5. For what number of patients with ischemic stroke is neurology consultation necessary?
None
Some
Most
All

6. Is stroke care better if a neurologist is involved as well as a hospitalist?

YES NO

7. Is stroke care better if a hospitalist is involved as well as a neurologist?

YES

$\mathrm{NO}$

Figure 1. Internal medicine hospitalist survey questions. $B P$ blood pressure; $E R$ extended-release; $I V$ intravenous; $L D L$ low-density lipoprotein; SBP systolic blood pressure; TIA transient ischemic attack. 
involved in all cases, with an additional 27\% (56) believing most of these patients should be seen by a neurologist. Interestingly, only $54 \%$ (111) reported that stroke care is better if a neurologist is involved in addition to a hospitalist, as opposed to $84 \%$ (117) who stated that stroke care is improved if a hospitalist is involved in addition to a neurologist.

- Among the physicians surveyed, many questioned the utility of neurologic consultation, although it is difficult to know whether this response was affected by the difficulty they have encountered in arranging for neurologic consultation. Only 37\% felt that all or most stroke patients need to be seen by a neurologist while in the hospital. If this assumption is correct, it may be helpful to develop criteria for neurologic consultation. However, given the national shortage of neurologists, as well as underinsurance, many stroke patients may never see a neurologist, even on an outpatient basis. The scarcity of neurologists means that in many hospitals, a neurologist is not available for the critical assessment and treatment decisions required in the first few hours of a stroke diagnosis.

- Despite the lack of demonstrated benefit of heparin, albeit with little demonstrated harm, the survey showed that 50\% (104) of the hospitalists would use it in acute stroke with atrial fibrillation. The vast majority $(91 \%$, or 188$)$ felt IV tPA is a proven treatment for acute stroke. Twelve percent (25) would prescribe an increased dose of aspirin for secondary prevention, whereas $23 \%$ (46) would change to clopidogrel and 63\% (129) would use aspirin/extended-release dipyridamole. This survey was performed before the PRoFESS (Prevention Regimen for Effectively Avoiding Second Strokes) study, which demonstrated near parity between the two in clinical effectiveness.

- At present, there is no clear evidence that hospitalists, neurologists, or a combination of the two provide the best care. Hospitalists vary in their perception of the value of and need for neurologist involvement in the care of most of their stroke patients. There is significant variability in specific elements of stroke care; however, hospitalists are surprisingly united in their support of IV tPA for stroke, especially when compared with emergency physicians. Although it would be difficult to establish specific criteria for neurologic consultation given the nature and spectrum of cerebrovascular disease, these expectations likely would be helpful to both neurologists and hospitalists and increase the care these patients receive.

- Given the variability in access to neurologists and the rapid increase in hospitalists, who now number up to 28,000 nationally, the actions hospitalists can take in acute stroke management include the following [19]:

- Become better trained in stroke care

- Partner with neurologists in the hospital 
- Push for increased organization and response times for stroke patients

- Help develop a stroke team and seek certification as a primary stroke center

- Establish a collaborative relationship with a regional stroke or tertiary care hospital

- Refine approaches to more rapidly identify and work up patients who experience a stroke while in the hospital

\section{Collaboration}

- The rapid evolution of stroke treatment and the time-sensitive needs of stroke patients provide a huge opportunity for hospitalists, neurohospitalists, and vascular neurologists to work together to care for stroke patients. This is especially true as office-based neurologists are increasingly unavailable to respond to neurologic emergencies in the hospital. Hospitalists are in a unique position to lead, coordinate, and participate in multidisciplinary teams working with neurohospitalists, neurointensivists, and vascular neurologists to reduce risk, to educate the public and institutional staff about the need for prompt response, and to develop pathways and guidelines for appropriate evaluation of risk and benefits of treatment. Thus, the goal is to develop a system in the hospital whereby the patient receives the best and timeliest stroke care. The development of multispecialty stroke services has been associated with reduced mortality in California hospitals [20]. Although the definition of multispecialty service likely varied among respondents to the survey, this type of service line development is aligned closely with hospitalist core competencies [13]. Indeed, service lines including physicians of multiple specialties as well as allied health professionals are integral to hospitalist practice [21•].

- Given the ongoing question regarding what care model might be most prevalent and effective, audiences attending the 2007 National Stroke Association regional conferences were asked several questions. Seventy-four percent of respondents (79 of 107) reported that a collaborative model of stroke care is the most common model at their institution; 82\% (95 of 116) felt that in 3 years, this model will be prevalent. Interestingly, $78 \%$ (86 of 110 ) had difficulty getting full coverage for stroke call [22]. In the opinion of those involved in the multiple stroke programs in the survey, the collaborative model appears to be common as well as durable.

\section{Disclosure}

Dr. Amin has received research support from and has been a speaker for Sanofi-Aventis. 
This article is distributed under the terms of the Creative Commons Attribution Noncommercial License which permits any noncommercial use, distribution, and reproduction in any medium, provided the original author(s) and source are credited.

\section{References and Recommended Reading}

Papers of particular interest, published recently, have been highlighted as:

- Of importance

•• Of major importance

1. $\quad$ Blacker DJ: In-hospital stroke. Lancet Neurol 2003, 29. (12):741-746.

2.• Lloyd-Jones D, Adams RJ, Brown TM, et al.: Heart disease and stroke statistics-2010 update. a report from the American Heart Association. Circulation 2010, 121:e54-e65.

This annual report reviews the range of risk factor control and the impact of stroke and heart disease in the United States. By doing so, there is both a summary of current cardiovascular disease and a predictor of what is to come.

3. The National Institute of Neurological Disorders and Stroke rt-PA Stroke Study Group: Tissue plasminogen activator for acute ischemic stroke. $N$ Engl J Med 1995, 333(24):1581-1587.

4. Zoppo GJ, Saver JL, Jauch EC, et al.: Expansion of the time window for treatment of acute ischemic stroke with intravenous tissue plasminogen activator: a science advisory from the American Heart Association/American Stroke Association. Stroke 2009, 40:2945-2948.

Several recent studies demonstrated both the safety and the efficacy of IV tPA in acute stroke beyond the 3-hour time window. The American Heart Association guidelines have been amended to endorse this change in practice. However, the eligibility criteria for treatment beyond 3 hours are more stringent.

5. Furlan A, Higashida R, Wechsler L, et al.: Intraarterial prourokinase for acute arterial ischemic stroke: the PROACT II study: a randomized controlled trial. Prolyse in Acute Cerebral Thromboembolism. JAMA 1999, 282:2003-2011.

6. Smith WS, Sung G, Starkman S, et al.: Safety and efficacy of mechanical embolectomy in acute ischemic stroke: results of the MERCI trial. Stroke 2005, 36(7):1432-1438.

7. Kulcsár Z, Bonvin C, Pereira VM, et al.: Penumbra system: a novel mechanical thrombectomy device for large-vessel occlusions in acute stroke. AJNR Am J Neuroradiol 2009 Dec 17 (Epub ahead of print).

8. Chaturvedi S, Bertasio B, Fernino L: Emergency physicians attitudes toward thrombolytic therapy in acute stroke. J Stroke Cerebrovas Dis 1998, 7(6):442-445.
Alberts MJ, Hademenos G, Latchaw RE, et al.: Recommendations for the establishment of primary stroke centers. Brain Attack Coalition. JAMA 2000, 283:3102-3109.

10. Schwamm LH, Pancioli A, Acker JE, et al.: Recommendations for the establishment of stroke systems of care. Stroke 2005, 36:690-703.

11. Alberts MJ, Latchaw RE, Selman WR, et al.: Recommendations for comprehensive stroke centers. A statement from the Brain Attack Coalition. Stroke 2005, 36:1597-1616.

12. Likosky D, Amin A: Who will care for our hospitalized patients? Stroke 2005, 36:1113-1114.

13. Pistoria MJ, Amin AN, Dressler DD, et al.: The core competencies in hospital medicine: a framework for curriculum development by the Society of Hospital Medicine. J Hosp Med 2006, 1(Suppl 1):2-95.

14. Rosamond W, Flegal K, Friday G, et al.: American Heart Association Statistics Committee and Stroke Statistics Subcommittee: Heart disease and stroke statistics: 2007 update: a report from the American Heart Association Statistics Committee and Stroke Statistics Subcommittee. Circulation 2007, 115:e69-e171.

15. Schwamm LH, Audebert HJ, Amarenco P, et al.: Recommendations for the implementation of telemedicine within stroke systems of care. A policy statement from the American Heart Association. Stroke 2009, 40(7):2635-2660.

16. Plauth 3rd WH, Pantilat SZ, Wachter RM, Fenton CL: Hospitalists' perceptions of their residency training needs: results of a national survey. Am J Med 2001, 111:247-254.

17. Smith MA, Liou JI, Frytak JR, Finch MD: 30-day survival and rehospitalization for stroke patients according to physician specialty. Cerebrovasc Dis 2006, 22(1):21-26.

18. Likosky DJ: The future of stroke care. Presented at the 2007 National Stroke Association Regional meetings. Nashville, TN; Sept 18, 2007. Cherry Hill, NJ; October 23, 2007. 
19. Beresford L: Spotlight on stroke. Available at http:// www.the-hospitalist.org/details/article/477345/Spot light_on_Stroke.html. Accessed March 6, 2010.

20. Birbeck GL, Zingmond DS, Cui X, et al.: Multispecialty stroke services in California hospitals are associated with reduced mortality. Neurology 2006, 66:1527-1532.

21. Peterson MC: A systematic review of outcomes and quality measures in adult patients cared for by hospitalists vs nonhospitalists. Mayo Clin Proc 2009, 84(3):248-254.
This article reviews the current literature on the benefits of hospitalist care over nonhospitalist care in several different settings. There is a general consensus that hospitalist care results in lower cost and length of stay, as well as improved clinical outcomes, when hospitalists are involved.

22. Likosky D, Chaturvedi S, Amin A: Hospitalist practice patterns in ischemic stroke care. Presented at the Society of Hospital Medicine Annual Meeting. San Diego, CA; April 3-5, 2008. 